\title{
SOSIALISASI PEMANFAATAN HASIL HUTAN BUKAN KAYU (HHBK) SEBAGAI SALAH SATU BENTUK PENGELOLAAN KHDTK KOTA PALANGKA RAYA
}

\section{(Socialization of Non Timber Forest Products Utilization as One of the Management of Forest Area with Special Purpose of Palangka Raya City)}

\author{
Nanang Hanafi, Fahruni dan Siti Maimunah \\ Program Studi Kehutanan Fakultas Pertanian dan Kehutanan \\ Universitas Muhammadiyah Palangkaraya \\ JI. RTA Milono Km.1,5 Palangka Raya, Kalimantan Tengah 73111 \\ e-mail : nananghanafi@gmail.com \\ fahruni@yahoo.co.id \\ sitimararil@gmail.com
}

\begin{abstract}
Socialization of non-timber forest product utilization as one form of the management of forest area with special purpose of Palangka Raya City is implemented and centered in meeting hall of Mungku Baru sub-distict of Rakumpit of Palangka Raya city. The socialization was conducted using the funding of fiscal inthe year of 2015. The socialization was conducted using lecturing and training methods. Training is provided with pedagogical methods that include lecture, demonstration and discussion methods.

The purpose of community service is creating of awareness and participation of the people around the forest area with special purpose to take care of and utilize the forest products sustainably; empowerment and participation of the people around forests aimed at achieving sustainable forest resource management and improving the welfare of forest villagers. The target community in this socialization activity is the community in Mungku Baru Sub-District of Rakumpit of Palangka Raya City with their economic activity mostly still depend on the existence of forests and fields around the forest.

Non-timber forest products that can be utilized by the people such as gamor skin, honey, resin gum, and traditional medicines. Population of pilau/damar (Agathis borneensis) is very large in the forest education of University of Muhammadiyah Palangkaraya, which is spread naturally in an area of approximately 2,500 $\mathrm{Ha}$. The resin copal can be harvested without damaging and cutting down trees, so that forest conservation can be maintained. University of Muhammadiyah Palangkaraya as one of the forest managers of education is committed to help the welfare of the villagers around the forest. Cooperation system offered is buying and selling resin copal.
\end{abstract}

Keywords: non-timber forest products, Forest Education University of Muhammadiyah Palangkaraya

\section{Abstrak}

Sosialisasi pemanfaatan hasil hutan bukan kayu (HHBK) sebagai salah satu bentuk pengelolaan Kawasan Hutan Dengan Tujuan Khusus (KHDTK) Kota Palangka Raya ini dilaksanakan dan dipusatkan di Balai Pertemuan Kelurahan Mungku Baru Kecamatan Rakumpit Kota Palangka Raya. Sosialisasi dilaksanakan menggunakan pendanaan Tahun Anggaran 2015, Sosialisasi dilaksanakan menggunakan metode ceramah dan pelatihan. Pelatihan diberikan dengan metode pedagogi yang meliputi metode ceramah, demonstrasi dan diskusi.

Tujuan pengabdian kepada masyarakat ini adalah terciptanya kesadaran dan partisipasi masyarakat di sekitar KHDTK untuk menjaga dan memanfaatkan hasil hutan secara lestari; pemberdayaan dan partisipasi masyarakat di sekitar hutan yang bertujuan untuk mencapai pengelolaan sumber daya hutan yang lestari dan peningkatan kesejahteraan masyarakat desa hutan. Masyarakat sasaran pada kegiatan sosialisasi ini adalah masyakat di Kelurahan Mungku Baru Kecamatan Rakumpit Kota Palangka Raya dengan kegiatan perekonomian mereka sebagian besar masih bergantung pada keberadaan hutan dan ladang di sekitar hutan.

HHBK yang dapat dimanfaatkan oleh masyarakat seperti kulit gamor, madu, getah damar, dan obat-obatan tradisional. Populasi pilau/damar (Agathis borneensis) sangat besar di hutan pendidikan UM Palangkaraya, yaitu tersebar secara alami di lahan seluas sekitar $2.500 \mathrm{Ha}$. Kopal damar dapat dipanen tanpa merusak dan menebang pohon, sehingga kelestarian hutan dapat terjaga. UM Palangka Raya sebagai salah satu pengelola hutan pendidikan berkomitmen membantu kesejahteraan masyarakat desa sekitar hutan. Sistem kerja sama yang ditawarkan adalah jual beli kopal damar.

Kata kunci : hasil hutan bukan kayu, Hutan Pendidikan UM Palangkaraya 


\section{PENDAHULUAN}

\section{Analisis Situasi}

Kawasan Hutan di Kelurahan Mungku Baru Kecamatan Rakumpit Kota Palangka Raya Provinsi Kalimantan Tengah adalah sangat heterogen, yang berada pada ketinggian sekitar $60 \mathrm{~m} \mathrm{dpl}$ (meter di atas permukaan laut) dengan topografi perbukitan dan memiliki beberapa aliran sungai kecil (Sub DAS) sehingga memiliki tipe hutan yang bervariasi. Sebagian besar kawasan ini merupakan hutan dipterokarpa dataran rendah (lowland dipterokarpa forest) yang masih alami. Selain itu, ada juga hutan rawa gambut dan hutan kerangas yang berada di sekitar daerah aliran Sungai Rakumpit dan Sungai Lais (Sub DAS Rungan).

Berdasarkan Surat Keputusan Menteri Kehutanan Republik Indonesia Nomor 611/Menhut-II/2014 tanggal 08 Juli 2014 tentang Penetapan Kawasan Hutan Dengan Tujuan Khusus (KHDTK) sebagai Hutan Pendidikan pada Kawasan Hutan Produksi Tetap di Kota Palangka Raya Provinsi Kalimantan Tengah seluas \pm 4.910 Ha (empat ribu sembilan ratus sepuluh hektar) dimana pengelolaannya dilimpahkan kepada Universitas Muhammadiyah Palangkaraya. Kawasan KHDTK tersebut merupakan kawasan yang mempunyai keanekaragaman hayati yang sangat beragam dan sebagian kecil mulai rusak yang diakibatkan oleh aktivitas masyarakat untuk penambangan dan perladangan berpindah, pembukaan akses jalan oleh perusahaan pemegang ijin konsesi di perbatasan kawasan dengan Kabupaten Gunung Mas. Selain itu keberadaan hutan adat ulin yang berada di dekat kawasan hutan pendidikan tersebut, perlu adanya pembinaan pengelolaan hutan adat untuk masyarakat di sekitar hutan, agar hutan ulin dapat terjaga dan lestari.

\section{Permasalahan}

Kawasan Hutan Dengan Tujuan Khusus (KHDTK) sebagai Hutan Pendidikan pada Kawasan Hutan Produksi Tetap di Kota Palangka Raya Provinsi Kalimantan Tengah seluas \pm 4.910 ha sangat rentan terhadap terjadinya perambahan hutan, pencurian kayu, pembukaan hutan untuk perladangan, kebakaran hutan, dan sebagainya, sehingga perlu adanya keterlibatan berbagai pihak dalam membantu mengatasi berbagai permasalahan yang ada sehingga tujuan pengelolaan Kawasan Hutan Dengan Tujuan Khusus (KHDTK) dapat terwujud dengan baik.

\section{Tujuan}

Tujuan pelaksanaan kegiatan pengabdian kepada masyarakat ini adalah menyelenggarakan pendampingan masyarakat berbentuk sosialisasi pemanfaatan hasil hutan bukan kayu (HHBK). Tujuan kegiatan sosialisasi yang dilaksanakan adalah:

1. meningkatkan kesadaran dan partisipasi masyarakat di sekitar Kawasan Hutan Dengan Tujuan Khusus (KHDTK) Kota Palangkaraya untuk menjaga dan memanfaatkan hasil hutan secara lestari,

2. meningkatkan pemberdayaan dan partisipasi masyarakat di sekitar hutan yang bertujuan untuk mencapai pengelolaan sumber daya hutan yang lestari, dan

3. peningkatan kesejahteraan masyarakat desa hutan khususnya masyarakat Kelurahan Mungku Baru Kecamatan Rakumpit Kota Palangka Raya. 


\section{METODE PELAKSANAAN}

\section{Waktu dan Tempat}

Kegiatan pengabdian kepada masyarakat berbentuk sosialisasi pemanfaatan hasil hutan bukan kayu (HHBK) ini dilaksanakan dengan dukungan pendanaan pada Tahun Anggaran 2015. Lokasi sosialisasi pemanfaatan hasil hutan bukan kayu dipusatkan di Balai Pertemuan Kelurahan Mungku Baru Kecamatan Rakumpit Kota Palangka Raya bersama warga masyarakat Kelurahan Mungku Baru Kecamatan Rakumpit Kota Palangka Raya.

\section{Sasaran Kegiatan}

Masyarakat sasaran pada kegiatan pengabdian kepada masyarakat berbentuk sosialisasi pemanfaatan hasil hutan bukan kayu (HHBK) ini adalah masyakat di Kelurahan Mungku Baru Kecamatan Rakumpit Kota Palangka Raya. Kegiatan perekonomian masyarakat sasaran sebagian besar masih bergantung pada keberadaan hutan dan ladang di sekitar hutan.

\section{Metode Kegiatan}

Metode yang digunakan pada kegiatan pengabdian kepada masyarakat berbentuk sosialisasi pemanfaatan hasil hutan bukan kayu (HHBK) ini dengan metode ceramah dan pelatihan. Pelatihan diberikan dengan metode pedagogi yang meliputi metode ceramah, demonstrasi dan diskusi.

\section{Solusi yang Ditawarkan}

Solusi yang ditawarkan akibat pelaksanaan kegiatan pengabdian kepada masyarakat ini adalah;

1. Masyarakat mendapatkan pendampingan dalam bentuk sosialisasi pemanfaatan hasil hutan bukan kayu (HHBK).
2. Terdapat peningkatan kesadaran dan partisipasi masyarakat di sekitar KHDTK Kota Palangka Raya untuk menjaga dan memanfaatkan hasil hutan secara lestari.

3. Terdapat peningkatan pemberdayaan dan partisipasi masyarakat di sekitar hutan yang bertujuan untuk mencapai pengelolaan sumber daya hutan yang lestari.

4. Terdapat peningkatan kesejahteraan masyarakat desa hutan khususnya masyarakat Kelurahan Mungku Baru Kecamatan Rakumpit Kota Palangka Raya.

\section{HASIL DAN PEMBAHASAN}

Kegiatan pengabdian kepada masyarakat yang dilakukan yaitu sosialisasi pemanfaatan Hasil Hutan Bukan Kayu (HHBK) sebagai salah satu bentuk pengelolaan KHDTK Kota Palangka Raya. Berdasarkan data sekunder dari BPS Kota Palangka Raya dan hasil observasi ke lokasi studi, Kelurahan Mungku Baru merupakan salah satu kelurahan di Kecamatan Rakumpit Kota Palangka Raya, dengan jumlah penduduk \pm 618 jiwa yang terdiri dari 326 jiwa penduduk laki-laki dan 292 jiwa penduduk perempuan. Luas wilayah Kelurahan Mungku Baru sebesar 187,25 Km², dan terdapat 4 sungai didalamnya, yaitu Sei Takaras, Sei Rakumpit, Sei Hambie, dan Sei Mungku (Kecamatan Rakumpit Dalam Angka, 2015). Sumber penerangan rumah tangga berupa non PLN, sebagian menggunakan solar panel untuk penerangan di malam hari dan sebagian lagi menggunakan genset.

Kondisi saat ini, di dalam hutan pendidikan telah dibuka akses jalan yang dibangun oleh pihak persahaan swasta yang memiliki izin lokasi di Kabupaten Gunung Mas (PT. Taiyong Engreen) 
berdasarkan Kepmenhut No. SK. 78/MenhutII/2009 tanggal 5 Maret 2009, di dalam lokasi Hutan Pendidikan terdapat lokasi indikatif penundaan pemberian izin baru/moratorium kehutanan seluas \pm 2.615 ha berdasarkan Peta Indikatif Penundaan Pemberian Izin Baru Pemanfaatan Hutan, Penggunaan Kawasan Hutan dan Perubahan Peruntukan Kawasan Hutan dan Areal penggunaan Lain - Revisi V (Lampiran Keputusan Menteri Kehutanan RI No. SK. 6018/Menhut-II/2013 tanggal 13 November 2013. Berdasarkan lampiran peta SK Menteri Kehutanan Nomor 611/Menhut-II/2014 tanggal 08 Juli 2014 tentang Penetapan Kawasan Hutan Dengan Tujuan Khusus sebagai Hutan Pendidikan pada Kawasan hutan Produksi Tetap di Kota Palangka Raya Provinsi Kalimantan Tengah seluas \pm 4.910 ha terdiri dari hutan rawa primer, hutan rawa sekunder bekas tebangan, hutan lahan kering sekunder bekas tebangan, semak belukar rawa dan semak belukar.

Sebagian besar masyarakat Kelurahan Mungku Baru menggantungkan hidupnya dengan bekerja sebagai petani. Bertani atau berladang merupakan mata pencaharian pokok masyarakat disamping mata pencaharian sampingan berupa : mencari ikan di sungai, bekerja sebagai penambang emas dan pasir puya, dan berburu satwa. Masyarakat Mungku Baru sangat bergantung pada keberadaan hutan. Bagi masyarakat Mungku Baru, hutan merupakan tempat penyedia sebagian kebutuhan mereka, misalnya tempat atau lahan untuk berladang, penghasil HHBK yang dapat dimanfaatkan oleh masyarakat seperti kulit gamor, madu, getah damar, obat-obatan tradisional dan lain sebagainya.

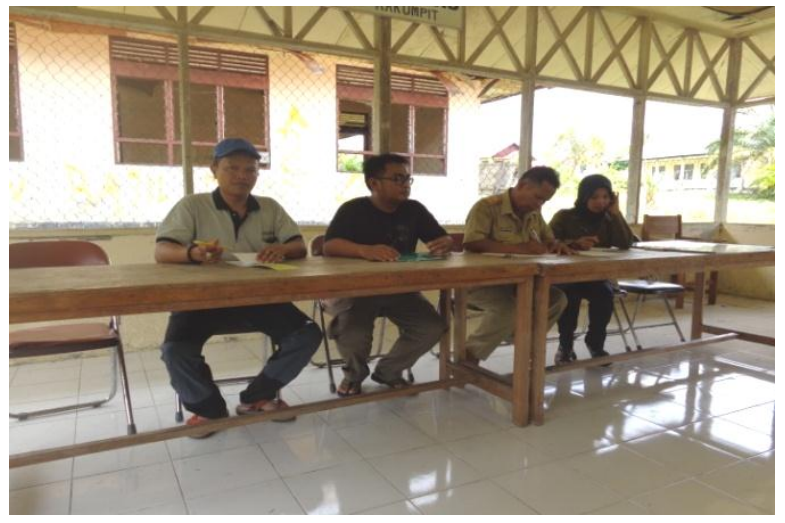

Gambar 1. Lurah Mungku Baru bersama tim pengabdian kepada masyarakat membuka kegiatan sosialisasi pemanfaatan hasil hutan bukan kayu

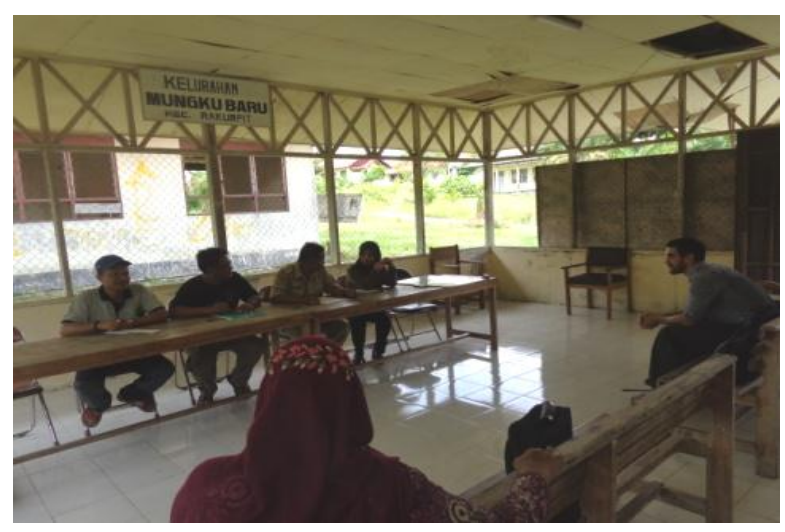

Gambar 2. Lurah Mungku Baru, Tim Pengabdian Kepada Masyarakat dan Tenaga Ahli memberikan materi sosialisasi pemanfaatan hasil hutan bukan kayu

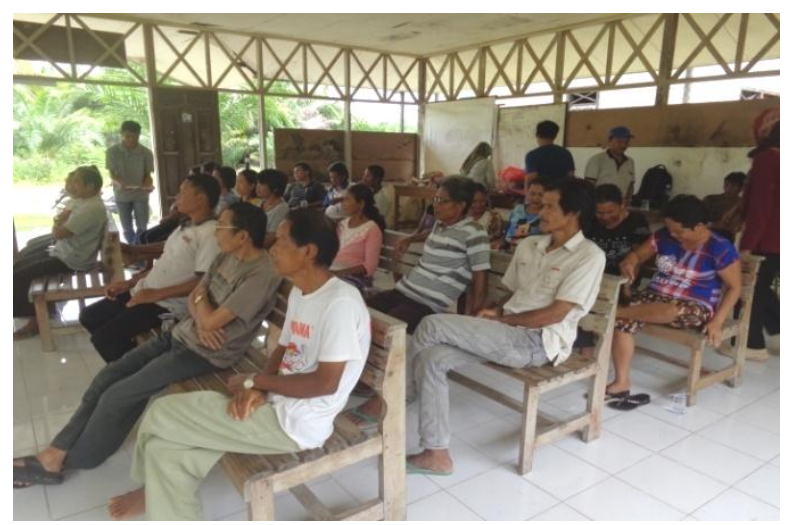

Gambar 3. Masyarakat Kelurahan Mungku Baru sebagai masyarakat sasaran mengikuti pemaparan materi sosialisasi pemanfaatan hasil hutan bukan kayu 


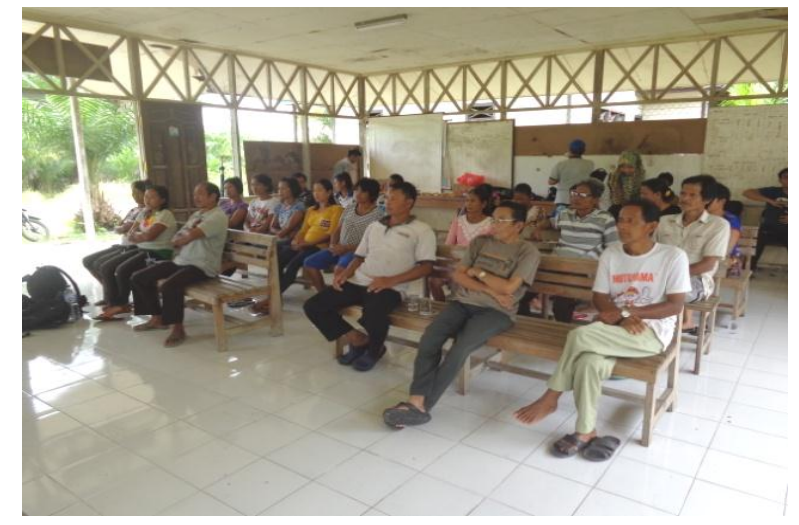

Gambar 4. Masyarakat Kelurahan Mungku Baru mengikuti pemaparan materi sosialisasi pengumpulan dan penjualan hasil hutan bukan kayu

Populasi pilau/damar (Agathis borneensis) sangat besar di hutan pendidikan UM Palangkaraya, yaitu tersebar secara alami di lahan seluas \pm 2.500 ha. Kopal damar dapat dipanen tanpa merusak dan menebang pohon, sehingga kelestarian hutan dapat terjaga. Selain itu masyarakat di sekitar hutan dapat memperoleh penghasilan tambahan dari hutan tanpa harus merusak hutan. Pemberdayaan masyarakat di sekitar hutan mempunyai tujuan untuk mencapai pengelolaan sumberdaya hutan yang lestari dan juga peningkatan kesejahteraan masyarakat di sekitar hutan.

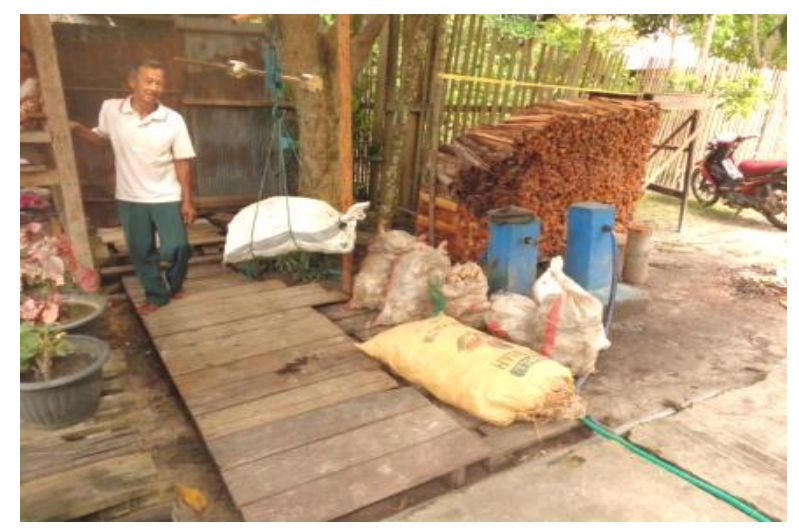

Gambar 5. Kondisi fasilitasi pengumpulan dan penjualan kopal damar di Kelurahan Mungku Baru Kecamatan Rakumpit Kota Palangka Raya
UM Palangka Raya sebagai salah satu pengelola hutan pendidikan berkomitmen membantu kesejahteraan masyarakat desa sekitar hutan. Sistem kerja sama yang ditawarkan adalah jual beli kopal damar. Masyarakat sekitar hutan sebagai pengumpul kopal damar dan pihak UM Palangka Raya sebagai pembelinya. Harga yang ditawarkan Rp. 2.500 per $1 \mathrm{~kg}$ kopal damar.

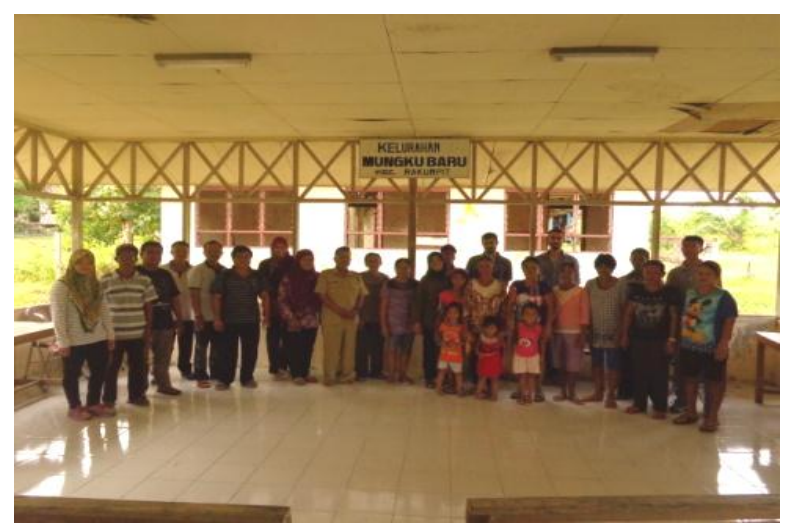

Gambar 6. Setelah acara tim pengabdian kepada masyarakat berfoto bersama masyarakat sasaran di Kelurah Mungku Baru Kecamatan Rakumpit Kota Palangka Raya

\section{SIMPULAN DAN SARAN}

\section{Simpulan}

Simpulan yang didapat dari hasil kegiatan kepada masyarakat ini adalah :

a. Masyarakat Kelurahan Mungku Baru Kecamatan Rakumpit Kota Palangka Raya sangat antusias dengan program yang ditawarkan.

b. Masyarakat pengumpul getah damar menjual getah damar ke pengepul dengan harga jual Rp. 1.300;/kg, sedangkan yang ditawarkan UM Palangkaraya sebesar Rp. 2.000; - 2.500;/kg. 
c. Keberlanjutan dari program ini adalah banyaknya masyarakat di Kelurahan Mungku Baru Kecamatan Rakumpit Kota Palangka Raya yang bekerja sebagai pengumpul kopal damar.

d. Kebiasaan masyarakat yang membuka hutan untuk kegiatan perladangan dapat berkurang dan kelestarian hutan dapat terjaga karena masyarakat diharapkan turut berperan aktif dalam menjaga keberadaan hutan sebagai sumber kesejahteraan mereka.

\section{Saran}

Saran yang diberikan setelah kegiatan ini adalah agar disediakan anggaran yang besar karena sangat diperlukan untuk keberlanjutan program ini sehingga UM Palangkaraya selaku pihak pengelola KHDTK Kota Palangka Raya di Kelurahan Mungku Baru Kecamatan Rakumpit mampu menjaga hutan pendidikan dan berkewajiban membina masyarakat di sekitar hutan pendidikan secara berkelanjutan karena keberhasilan menjaga kelestarian hutan akan menjadi hal yang mustahil tanpa pelibatan masyarakat yang tinggal di sekitar hutan.

\section{UCAPAN TERIMA KASIH}

Ucapan terima kasih disampaikan kepada Universitas Muhammadiyah Palangkaraya yang telah membantu pendanaan pembiayaan kegiatan pengabdian kepada masyarakat pada Tahun Anggaran 2015. Terimakasih juga disampaikan kepada Lurah Mungku Baru dan masyarakat Kelurahan Mungku Baru Kecamatan Rakumpit Kota Palangka Raya dan pihak lainnya yang secara aktif berpartisipasi pada kegiatan sosialisasi ini.

\section{DAFTAR PUSTAKA}

BPS. 2015. Kecamatan Rakumpit Dalam Angka 2015. BPS Kota Palangka Raya.

$\mathrm{H}$ de Foresta, A. Kusworo, A. Michon dan WA Djatmiko. 2000. Ketika kebun berupa hutan - Agroforest khas Indonesia - Sumbangan masyarakat bagi pembangunan berkelanjutan. International Centre for Research in Agroforestry, Bogor, Indonesia; Institut de Recherche pour le Développement, France; dan Ford Foundation, Jakarta, Indonesia.

Hairiah K., Sardjono, M.A., Sabarudin, S., 2003. Pengantar Agroforestri (Bahan Ajaran Agroforestri 1) World Agroforestry Centre (ICRAF) Southeast Asia. Bogor. Indonesia. 